\title{
KONFLIK BATIN DAN NILAI PENDIDIKAN NOVEL DI TANAH LADA KARYA ZIGGY ZEZSYAZEOVIENNAZABRIZKIE SERTA RELEVANSINYA DENGAN PEMBELAJARAN SASTRA DI SMA
}

\author{
Wafda Nurul Imani ${ }^{1}$, Nugraheni Eko Wardani' ${ }^{2}$, Herman J. Waluyo ${ }^{3}$ \\ Universitas Sebelas Maret \\ Email: wafdanurul@student.uns.ac.id ${ }^{1}$,nugraheniekowardani_99@yahoo.co.id ${ }^{2}$, \\ herman.jwaluyo@yahoo.co.id ${ }^{3}$
}

\begin{abstract}
Abstrak: Penelitian ini bertujuan untuk mendeskripsikan: (1) perwatakan para tokoh utama; (2) Id dalam konflik batin para tokoh; (3) Ego dalam konflik batin para tokoh; (4) Super ego dalam konflik batin para tokoh; (5) nilai pendidikan; dan (6) relevansi novel Di Tanah Lada dengan pembelajaran sastra di SMA. Metode yang digunakan kualitatif deskriptif. Sumber data yang digunakan berupa dokumen dan informan. Teknik pengambilan sampel menggunakan purposive sampling. Teknik pengumpulan data menggunakan teknik analisis dokumen dan wawancara. Validitas data dilakukan dengan triangulasi teori dan triangulasi sumber. Analisis data menggunakan analisis interaktif. Hasil penelitian dapat diuraikan sebagai berikut. (1) Perwatakaan para tokoh dalam novel Di Tanah Lada digambarkan secara variatif, baik secara jenis tokoh maupun dari segi dimensi fisiologis, psikologis, dan sosiologis; (2) Id dalam konflik batin yang dialami tokoh meliputi, menuruti pemikiran liar dalam kepala, mengabaikan wejangan orang tua, dan menuruti kesenangan secara implusif; (3) Ego dalam konflik batin yang dialami tokoh meliputi memuaskan rasa ingin tahu dan merasa bersalah atas keputusan yang diambil; (4) Super ego dalam konflik batin yang dialami tokoh meliputi, , mengalah demi kebaikan bersama, membantu orang dalam kesulitan, menerima resiko atas perbuatannya; (5) Nilai pendidikan dalam novel Di Tanah Lada didominasi oleh nilai pendidikan sosial; (4) Novel Di Tanah Lada telah memenuhi standar kelayakan isi, bahasa, penyajian, dan grafika serta dapat direlevansikan dalam pembelajaran sastra kelas XI.
\end{abstract}

Kata kunci: konflik batin, nilai pendidikan, novel Di Tanah Lada, pembelajaran sastra

\section{INNER CONFLICT AND EDUCATIONAL VALUES OF NOVEL DI TANAH LADA KARYA ZIGGY ZEZSYAZEOVIENNAZABRIZKIE AND ITS RELEVANCE TO LITERATURE LEARNING IN THE SENIOR HIGH $S C H O O L$}

\begin{abstract}
This study aims to describe: (1) characterization of the characters; (2) id from the inner conflicts of the characters; (3) ego from the inner conflicts of the characters; (4) super ego from the inner conflicts of the characters; (5) educational value; and (6) the relevance of novels Di Tanah Lada as the study for literacy in high school. The method used is descriptive qualitative. The sources come from documents and informants. The sampling technique uses purposive sampling. Writer used document analysis and interview techniques to collect data. Validation of the data is done by theory of triangulation and source triangulation. Analysis of the data used an interactive analysis technique. The results of the study can be described as follows. (1) The character of the characters in the novel Di Tanah Lada is varied, both in terms of character types and physiological, psychological and sociological dimensions; (2) Id in the inner conflict experienced by the character includes the pleasure of labeling others, conforming wild thoughts in the head, ignoring parental advice, and indulging indulgence in pleasure; (3) The ego in the inner
\end{abstract}

BASASTRA Jurnal Bahasa, Sastra, dan Pengajarannya

Volume 8 Nomor 2, Oktober 2020, P-ISSN 2302-6405, E-ISSN 2714-9765 
conflicts experienced by the characters includes fulfilling curiosity and feeling guilty for the decision that's been taken; (4) Superego in the inner conflicts experienced by the characters include, recognizing the risk of his decision, succumbing to the common good, helping people in trouble, accepting the risk of their actions; (5) Educational values in drama scripts consist of religious, moral, social and cultural education values. The value of education is being dominated by the value of social education; (4) Novels Di Tanah Lada has been meet the standards for content, language, presentation, and graphic worthiness and can be pertained in literacy learning in class XI.

Keywords: inner conflict, educational value, Di Tanah Lada novel, literature learning

PENDAHULUAN

Karya sastra merupakan suatu media yang digunakan pengarang untuk menyampaikan gagasan-gagasan atau pengalamannya kepada pembaca. Sebagai hasil kreativitas manusia, terciptanya karya sastra berkaitan erat dengan kehidupan pengarang. Sebagaimana dikatakan Endaswara (2013:96) bahwa karya sastra merupakan produk suatu kejiwaan dan pemikiran pengarang dalam situasi setengah sadar (subconscious) yang diolah dan dituangkan ke dalam bentuk sadar (conscious).

Sastra dan psikologi merupakan dua hal yang saling terkait. Psikologi sastra merupakan kajian yang memandang karya sastra sebagai aktivitas kejiwaan. Suatu karya sastra dapat menjadi ungkapan perasaan pengarang yang mengandung cipta, rasa dan karya. Begitu pula pembaca dalam menanggapi suatu karya, tidak mungkin lepas oleh kejiwaan masingmasing. Psikoanalisis adalah psikologi ketidaksadaran, perhatiannya berpusat pada aspek-aspek motivasi, emosi, konflik, mimpi, dan sifat atau karakter.
Keterkaitan konflik dalam kajian psikologi sastra merupakan pertentangan yang terjadi di dalam pikiran seorang tokoh. Suatu karya sastra melibatkan tokoh yang hidup di dalamnya. Menurut Kasnadi dan Sutejo (2010:12) tokoh merujuk pada aktor (pelaku) yang ada di dalam cerita fiksi, sedangkan penokohan berhubungan dengan karakter atau watak tokohnya. Pertentangan ini terjadi karena adanya perbedaan prinsip antara kesenangan dengan nilai-nilai yang tertanam dalam diri. Sebagaimana sifat dasar konflik yang selalu menuntut penekanan pada salah satu pihak, sehingga timbul ketidaknyamanan pada diri seseorang. Pertentangan ini lebih dikenal dengan istilah konflik batin.

Karya sastra selain memiliki fungsi menghibur, ia juga memiliki fungsi pendidikan. Wellek dan Werren (2014:156) menyatakan bahwa "kita tidak dapat memahami dan menganalisis karya sastra tanpa preferensi nilai" membuktikan bahwa kedudukan nilai memiliki kedudukan yang penting. Nilai pendidikan mengandung nilai-nilai yang mampu mendorong seseorang untuk berubah menjadi pribadi yang religius,

BASASTRA Jurnal Bahasa, Sastra, dan Pengajarannya

Volume 8 Nomor 2, Oktober 2020, P-ISSN 2302-6405, E-ISSN 2714-9765 
bermoral, berbudaya dan berjiwa sosial. Nilai-nilai tersebut perlu ditanamkan dalam diri setiap orang. Melalui pembelajaran sastra di sekolah, siswa diharapkan mampu meresapi nilai-nilai yang tersirat dalam suatu kaya sastra.

Di Indonesia pembelajaran sastra merupakan materi yang tercakup dalam mata pelajaran bahasa Indonesia. Materi ini terdapat di setiap jenjang pendidikan dengan porsinya masingmasing. Pembelajaran teks sastra dapat melibatkan informasi yang tersimpan lengkap mengenai warisan, sifat, pengaruh dan hubungan antara teks dan konteks yang membentu budaya sastra.

\section{Pembelajaran}

sastra

membutuhkan sumber belajar bagi peserta didik, dalam hal ini novel menjadi salah satu bahan ajar dalam pembelajaran sastra. Pemilihan novel yang digunakan sebagai sumber belajar tidak dapat dilakukan secara sembarangan. Menentukan bahan ajar perlu memperhatikan isi konten yang terkandung di dalamnya.

Novel Di Tanah Lada karya Ziggy Z. merupakan salah satu novel yang mengandung aspek kejiwaan dan nilai-nilai pendidikan. Yang paling menarik dalam novel ini adalah sudut pandang yang dipilih penulis menggunakan sudut pandang orang pertama dan dijabarkan melalui cara pandang anak berusia enam tahun dalam melihat setiap hal (Sartika \& Ermanto, 2018). Salva merupakan tokoh utama dalam cerita yang banyak mengalami pertentangan bantin saat belajar mengenal kehidupan. Salva sering kali bersikap dan berpikir di luar kemampuan anak seusianya. Hal tersebut disebabkan berbagai permasalahan rumit yang dihadapinya. Di Tanah Lada mengemas cerita dalam bentuk yang unik dan imajinatif, namun sesungguhnya novel ini berusaha menggambarkan masalah sosial dan kriminalitas yang sering kita temui di surat kabar (Ridwan, 2018). Permasalahan utama yang diangkat dalam novel ini mengarah pada kekerasan dalam rumah tangga dan kekerasan pada anak. Novel ini mungkin saja mengena dengan masalah-masalah sosial yang banyak dialami oleh anak-anak Indonesia khususnya anak-anak yang berasal dari kondisi ekonomi menengah ke bawah. Novel ini mengandung nilai-nilai pendidikan secara tersurat maupun tersirat. Mengangkat berbagai isu-isu sosial dengan sudut pandang anak kecil membuat novel ini menjadi Pemenang II Sayembara Menulis Novel Dewan Kesenian Jakarta 2014.

Berdasarkan paparan-paparan di atas, alasan pememilihan novel $D i$ Tanah Lada karya Ziggy Zezsyazeoviennazabrizkie sebagai objek penelitian karena novel ini sangat menarik jika dilihat dari aspek kejiwaan dan diharapkan pemaparan nilai-nilai pendidikan yang terkandung dalam novel dapat memberikan manfaat bagi semua pihak.

\section{METODE}


Penelitian ini adalah deskriptif kualitatif dengan metode content analysis atau analisis isi. Penelitian ini mendeskripsikan atau menggambarkan apa yang menjadi masalah, kemudian menganalisis dan menafsirkan data yang ada. Metode content analysis atau analisis isi yang digunakan untuk menelaah isi dari suatu dokumen.

Data penelitian ini diperoleh dari hasil telaah novel Di Tanah Lada karya Ziggy Z. Siswantoro (2010: 72) berpendapat sumber data terkait dengan objek penelitian dari mana data diperoleh. Sumber data penelitin ini adalah sumber data primer yang digunakan dalam penelitian ini adalah novel Di Tanah Lada. Sumber data sekunder dalam penelitian ini adalah wawancara dengan narasumber. Informan dalam penelitian ini terdiri dari ahli sastra, guru bahasa Indonesia SMA, dan siswa SMA kelas XI yang sudah membaca novel ini.

Teknik pengambilan sampel yang digunakan dalam penelitian ini adalah purposive sampling. Siswantoro (2010: 73) menjelaskan purposive sampling adalah pengambilan sampel yang disesuaikan dengan tujuan penelitian. Teknik pengumpulan data dalam penelitian ini adalah menggunakan analisis dokumen dan wawancara untuk menjaring data secara lengkap dan akurat sehubungan dengan masalah yang diteliti.

Validitas data yang digunakan dalam penelitian ini, yaitu teknik triangulasi. Triangulasi merupakan pengecekan kebenaran dengan cara memperoleh data tersebut dari pihak atau sumber berbeda. Hal ini bertujuan untuk membandingkan informasi yang diperoleh dari berbagai pihak agar ada jaminan tentang tingkat kepercayaan atau kevalidan data. Penelitian ini menggunakan triangulasi teori. Triangulasi teori digunakan dengan cara rujuk silang antarteori (teori satu dengan yang lain) untuk mendapatkan teori yang benar-benar terpercaya agar dapat digunakan sebagai acuan dalam penelitian. Selain itu, peneliti juga menggunakan triangulasi sumber data, yaitu teknik pemeriksaan kebenaran data hasil analisis dengan mewawancarai informan yang berbeda tetapi membahas masalah yang sama.

Teknik analisis data yang digunakan dalam penelitian ini adalah teknik analisis interaktif (interactive model of analysis). Komponenkomponen analisis data meliputi: (1) periode pengumpulan data, (2) reduksi data, (3) penyajian data, dan (4) penarikan kesimpulan (Miles, Hubermen, \& Saldana, 2014).

\section{HASIL DAN PEMBAHASAN}

Penelitian ini merupakan penelitian kualitatif sehingga sangat diperlukan adanya deskripsi kata-kata untuk menyampaikan hasil temuannya. Temuan penelitian berupa data kualitatif, yakni kutipan kalimat yang ada pada novel Di Tanah Lada karya Ziggy Zezsyazeoviennazabrizkie. Analisis dilakukan pada tokoh dan penokohan, konflik batin, nilai 
pendidikan, serta relevansinya dengan pembelajaran sastra di SMA.

Tokoh dan Penokohan dalam Novel Di Tanah Lada Karya Ziggy Z.

Tokoh merupakan pelaku cerita yang menjadi jawaban atas pertanyaan "siapa" dalam sebuah cerita (Pujiharto, 2012: 43). Dalam novel Di Tanah Lada terdapat tujuh tokoh yang paling sering muncul dan banyak mempengaruhi jalannya cerita. Setiap tokoh memiliki kedudukan yang berbeda-beda dan karakter yang berbeda pula. Salva menjadi satu-satunya tokoh yang berkedudukan sebagai tokoh utama. Salva, Pepper, Doni, dan Papa Pepper menjadi tokoh yang memiliki karakter bulat. Karakter yang memiliki perkembangan yang signifikan atau tokoh berkembang adalah Salva dan Pepper. Kedudukan tokoh antagonis dipegang oleh Doni dan Papa Pepper.

\section{Konflik Batin id, ego dan super ego tokoh dalam novel Di Tanah Lada karya Ziggy $\mathbf{Z}$.}

Konflik batin yang dialami tokoh dianalisis oleh tiga faktor, $i d$, ego dan super ego. Id diibaratkan sebagai raja atau ratu, ia berlaku seperti penguasa absolut yang harus dituruti, sewenang-wenang dan memikirkan diri sendiri (Minderop, 2016:20). Ego berperan sebagai pemegang keputusan. ego mempertimbangkan tuntututantuntutan id dan superego yang bertentangan dan tidak realistik dengan keadaan realistik dari dunia luar
(Semium, 2006:64-65). Sedangkan super ego dijelaskan oleh Endaswara (2013:101) sebagai sistem pribadi yang berisi nilai-nilai atau aturan yang bersifat evaluatif (menyangkut baikburuk). Dalam novel di tanah lada ditemukan data sebagai berikut .

Seperti ada hantu yang menggentayangi seluruh bagian rumahku. Hanya saja, di dalam sini, hantunya hidup. Hidup, berbadan besar dan sangat menakutkan.

Nama hantunya Papa. (Id)

(1)

Kurasa Mama tidak akan senang kalau aku bilang Papa mirip hantu. (Super ego)

Tapi kurasa Mama tidak akan senang kalau aku bicara bohong. Jadi, kurasa lebih baik aku jujur. (Ego).

(Zesyazeoviennazabrizkie, 2015:2) Kurasa aku akan kena marah Papa begitu pulang nanti. Papa benci aku. Tapi dia lebih benci lagi kalau aku menguping. Aku sudah berusaha tidak menguping, tapi ternyata menguping itu asyik. (Id) (2)

Papa sudah berkali-kali menangkapku menguping. Setiap kali aku tertangkap, Papa akan menjewer telingaku dan memukul pantatku dengan sisir. (Super ego) Aku tidak mau dipukul sisir. Tapi sekarang tidak mungkin tidak menguping, soalnya suara Papa akan kedengaran ke mana pun aku pergi. Ruangan itu kan kecil. Aku 
tidak bisa ke mana-mana, kecuali (Zesyazeoviennazabrizkie, keluar. (Ego)

2015:59)

(Zesyazeoviennazabrizkie,

2015:19)

Aku tidak mau menunggu di rumah makan, tapi kalau aku tidak patuh, mungkin Mama akan jadi lebih sedih lagi.(Id) (3)

Padahal, sekarang dia sudah sangat sedih. Dan aku tidak mau membuat Mama sedih. Itu cukup jadi kerjaannya Papa saja. (Super ego)

Mama tampak sangat sedih sekarang. "Kunci pintu ada di Papa," bisik Mama lagi. "Mama tidak bisa memintanya. Кати bisa tunggu di rumah makan, sayang?" Aku mengangguk patuh. (Ego).

(Zesyazeoviennazabrizkie, 2015:36)

Jadi, aku keluar dari kamar. Aku bilang, "Hari ini, kamu mau ke mana?"

"Ke tempat Kak Suri," katanya. Dia menunjuk langit-langit.

"Kamarnya di lantai 4."

"Oh." Aku diam saja.

Dia memperhatikaku. Lalu, katanya, "Kamu mau ikut?"

Aku buru-buru mengangguk. (Ego) Aku tidak tahu siapa Kak Suri. Dan kata Mama, jangan suka ikutikut orang sembarangan. (Super ego) (5)

Tapi aku tidak tahu harus ke mana lagi. Lagi pula, Mama dan Papa juga sering membawaku menemui orang yang tidak kukenal. (Id) 
akan pernah ketemu Pepper lagi.(Id)

(Zesyazeoviennazabrizkie, 2015:158)

Data (1) menggambarkan penggalan peristiwa konflik batin yang dialami Salva, ketika ia menganalogikan papanya sebagai hantu. Pertentang terjadi saat mengingat mamanya yang tidak akan senang mendengar ia menyebut ayahnya dengan sebutan hantu, namun pada akhirnya ia tetam melabeli papanya dengan sebutan hantu. Keputusan Salva besar dipengaruhi oleh dorongan $i d$. Hal serupa terjadi pula pada data (4) dan (5).Pada data (4) Salva kembali menuruti dorongan id dalam dirinya untuk melanggar wejangan mamanya untuk tidak ikut dengan sembarangan orang. Dan pada data (5) Salva kembali melanggar super ego berupa kesadaran bahwa pergi tanpa mendapat izin dari mamanya adalah sesuatu yang tidak dibenarkan. Dominasi dorongan id dalam diri Salva disebabkan oleh usia Salva yang masih belia sehingga nilai akan benar dan salah masih merupakan sesuatu yang buram baginya. Hal ini sejala dengan penemuan Sartika \& Ermanto (2018) "The character of Salva is able to recognize her own emotion, but is unable to manage them properly" atau karakter Salva menunjukan sikap bahwa ia memahami emosi yang ada di dalam dirinya, akan tetapi sering kali ia tidak mampu mengelola emosinya dengan baik sehingga kesenangan menjadi tujuan utama dalam setiap pertentangan batin.

Pada data (6) menggambarkan emosi Salva yang secara seimbang tidak berpihak pada id maupun super ego. Salva berada di antara dilemma untuk kembali ke pelukan mamanya atau tetap ikut bersama Pepper meninggalkan Jakarta. Bersama Pepper adalah dorongan yang sangat kuat dan menuntut untuk dituruti, sedangkan mengabaikan mamanya menciptakan rasa bersalah yang amat sangat pada diri Salva. Setiap keputusan yang di ambil Salva selalu mempertimbangkan id maupun super ego. Faktor yang mempengaruhi pengambilan keputusan adalah faktor endogen berupa sifat bawaan indivdu sejak lahir dan faktor lingkungan yang datang dari lingkungan maupun pengalaman (Setiari \& Supriyanto, 2016).

$$
\text { Pada data (2) dan }
$$

pengambilan keputusan yang dilakukan Salva banyak mendapat dorongan dari super ego. Hal ini dapat dilihat pada data (2) bagaimana Salva mendahulukan kepentingan orang lain, yaitu mamanya agar beliau tidak merasa sedih sekalipun hal tersebut harus mengorbankan kesenangan Salva pribadi. Pada data (3) Salva menyadari resiko yang akan ia terima saat melakukan sesuatu yang tidak baik atau tidak disukai oleh papanya. Resiko atas sebuah perbuatan menjadi super ego yang melekat pada diri Salva, sehingga ia berpikir lebih matang sebelum mengambil sebuah keputusan. Pengambilan keputusan berdasarkan 
super ego yang tertanam dalam dirinya. Hal ini disebabkan oleh kemampuan Salva yang sangat baik dalam mengenali dan berempati dengan orang lain (Sartika \& Ermanto, 2018).

Tabel 1. Dominasi Aspek Kejiwaan Novel Di Tanah Lada Karya Ziggy Zezsyazeoviennazabrizkie

\begin{tabular}{llll}
\hline No & $\begin{array}{c}\text { Aspek } \\
\text { Kejiwaan }\end{array}$ & $\begin{array}{l}\text { Jumlah } \\
\text { Data }\end{array}$ & $(\%)$ \\
\hline 1 & Id & 3 & 50 \\
\hline 2 & Ego & 1 & 17 \\
\hline 3 & Super Ego & 2 & 33 \\
\hline 4 & Total & 6 & 100 \\
\hline
\end{tabular}

Pada tabel 1, terlihat bahwa secara kesuluruhan dalam mengambil keputusan tokoh lebih banyak mengandalakan aspek kejiwaan id yang berkaitan dengan kesenangan. Keputusan yang diambil berdasarkan aspek id sebanyak $50 \%$, berdasarkan ego sebanyak $17 \%$, dan berdasarkan super ego sebamyak $33 \%$.

\section{Nilai Pendidikan dalam Novel Di Tanah Lada karya Ziggy $Z$}

Novel sebagai gambaran kehidupan masyarakat tentunya mengandung maksud yang ingin disampaikan penulis kepada pembaca. Penyampaian maksud tersebut dilakukan secara tersirat dengan menyelipkan nilai-nilai pada sebagian peristiwa yang diceritakan. Nilai pendidikan dalam suatu karya sastra didapatkan dari proses memahami, menganalisis, serta mengapresiasi karya sastra tersebut (Fadli, Walyo, dan Suryanto, 2017:178).

\section{Nilai Pendidikan Religius}

(a)Aku juga tahu arti 'menggunjing' karena Bu Guru Agama bilang kita tidak boleh menggunjingkan orang. Menggunjing artinya membicarakan keburukan orang. Kalau kata 'menggunjingkan' disusul dengan kata 'Papa', itu berarti bisa termasuk: wajah, tutur kata, sikap, etika, hati, gaya berpakaian dan hidung.

(Zezsyazeoviennazabriz kie, 2015: 56)

(b)Aku menggeleng. "Aku mau makan kue sus-nya. Mama, kok, nggak makan buburnya? Dingin, lho. Kata Kakek Kia, ngga boleh menyia-nyiakan makanan. Kalau Mama tanam padinya sendiri, mama pasti kesusahan. Jadi, sudah untung ada yang menanamkan. Makanya, Mama harus makan semuanya sampai habis."

(Zezsyazeoviennazabriz kie, 2015: 56)

(c)Dan, kurasa, aku tahu alasan besar yang membuat semua orang dalam kehidupan $P$ memperlakukan dia seolah-olah dia bukan anak kecil. Bukan alasan Kak Suri, Mas Alri, Mama Asli P, atau Papa Palsu $P$. Tapi alasan yang dirangkai Tuhan. Alasan yang sesungguhnya. 
(Zezsyazeoviennazabriz

kie, 2015: 226)

Data (a) menunjukan nilai pendidikan religius bahwa menggunjingkan seseorang merupakan suatu perbuatan yang dilarang dalam agama yang diyakini tokoh tersebut. Data (b) menunjukan perbuatan membuang makanan adalah sebuah hal yang dilarang, atau lebih dikenal dengan istilah mubazir dan merupakan perbuatan yang tercela. Data (c) mengungkapkan keyakinan tokoh Salva akan takdir yang diberikan Tuhan kepada makhluknya. Keyakinan yang Salva tanamkan berakar pada nilai pendidikan religius yang melekat pada dirinya.

\section{Nilai Pendidikan Moral}

(d) "Hmm." Mama berpikir sebentar. "Pertama-tama, seharusnya selalu membantu orang tua ketika mereka masih hidup. Nenek Isma masih hidup, tapi Papa tidak pernah memberi uang ke Nenek Isma."

(Zezsyazeoviennazabriz kie, 2015: 7)

(e)Mama mengangguk. "Tapi, seharusnya Papa mengunjungi Kakek Kia. Karena Kakek Kia adalah Papa-nya Papa. Dan semua Papa suka dikunjungi anaknya, apalagi kalau mereka sudah tua dan seorang diri. Tidak ada yang suka merasa kesepian, begitu pula Kakek Kia. Mengunjungi orang tua merupakan cara untuk menunjukkan kalau kamu menyayangi mereka."

(Zezsyazeoviennazabrizk ie, 2015: 7)

(f) "Utang budi itu apa, Ma?"

Mama berpikir-pikir sebentar. "Utang budi itu, maksudnya kamu harus melakukan sesuatu kebaikan kepada seseorang yang telah melakukan kebaikan kepada kamu. Misalnya, kamu sudah menolong Mama belanja. Jadi, Mama harus berbuat baik kepada kamu sebagai balasannya."

(Zezsyazeoviennazabriz kie, 2015: 54)

Data (d) merupakan penjelasan tokoh Mama cara menghargai jasa orang tua yang telah membesarkan kita dengan membantunya secara materi. Hal ini Mama ajarkan pada Salva sebagai bekal nilai moral bagi Salva. Data (e) menungkapkan cara yang tepat dalam menunjukan kasih sayang kepada orang tua. Selain membantu secara materi, orang tua cenderung lebih mudah merasa kesepian dan membutuhkan kasih sayang secara langsung dari anak-anaknya. Data (f) merupakan nilai pendidikan moral yang diberikan tokoh Mama kepada Salva untuk membalas setiap kebaikan dengan kebaikan yang lebih banyak. Terutama kepada orang yang telah banyak membantu kita.

\section{Nilai Pendidikan Sosial}

(g)Haruskah aku memberinya uang? Aku masih punya banyak uang dari Papa. Papa 
memberiku dua lembar uang lima puluh ribuan, dan harga nasi ayam ini cuma sebelas ribu. Aku belum bisa menghitung sebanyak itu. Tapi melihat jumlah lembaran kertas di kantongku, aku tahu aku masih punya banyak uang.

(Zezsyazeoviennazabriz kie, 2015: 20)

(h)Di dalam ranselku, ada beberapa buah makanan. Aku selalu menyimpan makanan dalam ransel. Waktu kami mau pergi, aku mengambil banyak makanan dari rak maknaan kami di rumah. Aku mengeluarkan dua buah coklat batangan dan memberikan satunya kepada Si Anak Pengamen. Kurasa anak pengamen tidak sering makan coklat

(Zezsyazeoviennazabriz kie, 2015: 43)

(i) Tapi ternyata dia memotongkan ayamku, mencampurnya dengan nasi, lalu mengulurkan sendoknya ke mulutku. Aku kaget sekali-ternyata dia mau menyuapiku. Seperti mama. Lalu karena aku lapar, aku mulai makan.

(Zezsyazeoviennazabriz kie, 2015: 22)

(j) Aku mengangguk dan kami berdua berjalan ke kantin rumah sakit untuk makan mie instan dengan telur rebus. Pepper harus makan dengan tangan kiri, dan itu susah, jadi aku membantunya makan. Aku masih belum pandai dengan garpu, jadi aku menggunakan sendok untuk memotongmotong mi dan menyuapkan mi pendek ke Pepper.

(Zezsyazeoviennazabriz kie, 2015: 139)

Pada data (g) tampak nilai sosial berupa nilai empati yang besar yang dimiliki tokoh Salva pada orang di sekitarnya. Kepekaan sosial yang dimiliki tokoh Salva kembali ditampakkan pada data (h). Sebagai seorang anak yang berusia enam tahun, Salva merupakan sosok yang senang berbagi dengan sesama. Nilai pendidikan sosial yang tersirat pada data (i) adalah ketika seorang anak pengamen berusia sepuluh tahun (Pepper) dengan ringan membantu seorang anak berusia enam tahun (Salva) yang tidak dikenalnya sama sekali. Kedua tokoh menujukan nilai pendidikan sosial. Nilai pendidikan sosial yang ditunjukan Pepper adalah sikapnya yang ringan tangan dalam hal kebaikan dan Salva yang menunjukan nilai pendidikan sosial yaitu tidak berprasangka buruk terhadap orang hanya melalui penampilan luarnya saja. Pada data (j) menunjukan nilai pendidikan sosial saat Salva berusaha membantu Pepper, meskipun ia sendiri memiliki keterbatasan kemampuan.

\section{Nilai Pendidikan Budaya}

(k)Mama menatapku terkejut, "Lho, kamu belum pernah main bekel, ya? Ya sudah, nanti 
Mama ajari, deh. Kita beli bola bekel dan keongnya, ya?"

(Zezsyazeoviennazabrizk ie, 2015: 50)

Kerjaan Kakek Kia ketika muda adalah memancing ayam dari sungai hujan bersama anakanak kampung. Kadangkadang, ayam yang mereka dapat bisa sampai seratus ekor. Mereka berhenti kalau sudah capek. Tapi, mereka dapat bayak sekali ayam.

(Zezsyazeoviennazabrizk ie, 2015: 186)

Pada penggalan kutipan di atas, data (k) menunjukkan seorang ibu mengenalkan permainan tradisional kepada anaknya yang berusia enam tahun sehingga ia mengenal budaya yang melekat di Indonesia. Sedangkan data (1) menunjukan peristiwa seorang Kakek menceritakan budaya di tempat tinggalnya saat muda dulu kepada cucunya yang mungkin sudah tidak mengalami apa yang beliau alami saat muda Pelestarian budaya dapat dilakukan dengan berbagai cara, misalnya dengan kisah dari mulut ke mulut pada setiap generasi.

Tabel 2. Rincian Data Nilai-nilai Pendiidkan

\begin{tabular}{llll}
\hline No. & $\begin{array}{l}\text { Nilai } \\
\text { Pendidikan }\end{array}$ & $\begin{array}{l}\text { Jumlah } \\
\text { Data }\end{array}$ & $(\%)$ \\
\hline 1. & Religius & 3 & 25 \\
\hline 2. & Moral & 3 & 25 \\
\hline 3. & Sosial & 4 & 33 \\
\hline 4. & Budaya & 2 & 17 \\
\hline & Total & 12 & 00 \\
\hline
\end{tabular}

Tabel 2 menunjukan nilai pendidikan yang paling sering muncul ialah nilai pendidikan sosial. Hal ini sejalan dengan tema yang di angkat penulis, ialah isu sosial. Sehingga dominasi nilai pendidikan yang muncul sudah dapat diperkirakan sebelumnya.

\section{Relevansi Konflik Batin dan Nilai Pendidikan Novel Di Tanah Lada Dengan Pembelajaran Sastra di SMA}

Pengajaran sastra tidak bisa dipisahkan dari apresiasi sastra karena tujuan akhirnya dan esensi pengajaran sastra adalah terbinanya sikap apresiatif siswa, dimilikinya sikap batin yang postif terhadap karya sastra, dimilikinya kemampuan memahami makna dan merasakan keindahan cipta sastra yang mereka baca (Mujiyanto \& Fuady, 2010:11). Novel Di Tanah Lada merupakan novel yang mengandung nilai pendidikan dan sarat akan nilai kehidupan.

Novel ini menceritakan tentang cara seorang anak berusia enam tahun mengenali dunia. Tumbuh di keluarga yang utuh namun dengan kasih sayang yang tidak utuh membuat Salva memiliki kepekaan yang tinggi terhadap lingkungan dan orang-orang disekitarnya. Konflik batin utama yang sering muncul adalah dorongan untuk bertindak sesuka hati tanpa menyadari resiko dari keputusan yang diambilnya. Novel Di Tanah Lada karya Ziggy Z. telah dinilai dengan mengacu pada instrument kelayakan dan mendapat hasil bahwa novel ini layak 
dengan predikat baik. Secara luas, novel ini terbebas dari unsur SARA, dan hal-hal yang bertentangan dengan undang-undang. Kedua hal ini menjadi penting sebagaimana dinyatakan oleh Bachtiar dan Sihes (2016: 8) bahwa karya sastra yang baik menjamin kelengkapan unsur pembangunnya.

Tema sosial yang diangkat Ziggy Z. dalam novel Di Tanah Lada mampu menyentil kepekaan sosial siswa dan membuka wawasan lebih luas mengenai berbagai gambaran kehidupan. Bahasa yang digunakanpun dikemas secara sederhanadan mudah dipahami oleh anak-anak SMA saat ini. Selain itu, terdapat nilai-nilai pendidikan sosial yang terkandung di dalamnya yang menjadi sarana edukasi yang dapat dinikmati secara luas.

Dalam pembelajaran sastra, novel Di Tanah Lada dapat direlevansikan dengan Kompetensi Dasar 3.11 dan 4.11 mengenai analisis pesan dan menulis ulasan mengenai pesan yang ingin disampaikan dari suatu buku fiksi. Hal ini dilihat dari banyaknya pesan moral yang terkandung di dalam novel yang tersirat melalui nilai-nilai pendidikan dan pengambilan-pengambilan keputusan dalam pertentangan batin yang dialami tokoh.

Penggunaan novel Di Tanah Lada dapat dilakukan oleh seorang guru sebagai bahan pembelajaran adalah dengan meminta peserta didik membacanya kemudian menemukan konflik bantin dan nilai pendidikan yang terkandung di dalamnya, menyimpulkan amanat yang ingin disampaikan penulis kemudian dituangkan dalam bentuk sinopsis. Hal ini bertujuan membantu siswa berpikir tingkat tinggi dalam memahami isi maupun makna yang terkandung secara menyeluruh.

\section{SIMPULAN}

Berdasarkan pada hasil pengumpulan dan analisis data di atas, maka dapat disimpulan bahwa novel $D i$ Tanah Lada karya Ziggy Z. dapat dijadikan sebagai bahan ajar pembelajaran sastra di SMA. Khususnya mata pelajaran Bahasa Indonesia kelas XI. Pada novel tersebut ditemukan beragam karakteristik tokoh yang sesuai dengan latar belakang masingn-masing dan kedudukan dlam cerita. Ditemukan pula enam data konflik batin dengan dominasi id sebanyak 3 data, dominasi ego sebanyak 1 data dan dominasi super ego sebanyak 2 data.

Selain mengandung konflik batin yang kompleks, novel ini juga mengandung nilai pendidikan. Nilai pendidikan sendiri terdiri atas nilai pendidikan religius, moral, sosial dan budaya. Dari keempat nilai tersebut, novel ini di dominasi oleh nilai pendidikan sosial. Hal ini sesuai dengan isu yang diangkat dan amanat yang ingin disampaikan penulis. Novel Di Tanah Lada memiliki kriteria yang memenuhi standar kelayakan yang meliputi komponen isi, penyajian, bahasa dan grafika. Konflik-konflik batin yang muncul di dalamnya dapat 
dijadikan sebagai media edukasi dalam mempertimbangkan dan mengambil keputusan. Novel ini juga mengandung nilai-nilai pendidikan yang mampu menjadi sarana edukasi bagi siswa sekolah menengah atas. Oleh karena itu, disimpulkan bahwa novel Di Tanah Lada karya Ziggy Z. memiliki relevansi yang baik apabila dijadikan pembelajaran sastra di SMA.

\section{REFERENSI}

Bachtiar, E.S. \& Sihes, A.J. (2016). Kompetensi Kognitif Pembelajaran Apresiasi Sastra di Sekolah Dasar. Jurnal Gramatika, 5 (1), 1-11.

Endaswara, S. (2013). Metodologi Penelitian Sastra. Yogyakarta: Penerbit Pustaka Widyatama

Fadli, M., Waluoy, B., dan Suryanto, E. (2017). Analisis Struktural dan Nilai Pendidikan Novel Gedhong Setan Karya Suparto Brata serta Relevansinya sebagai Materi Pembelajaran Novel Berbahasa Jawa. Paedagogia, 20 (2), 166184.

Kasnadi dan Sutejo. (2010). Kajian Prosa Kiat Menyisir Dunia Prosa. Yogyakarta: Pustaka Felicha.

Minderop, A. (2016). Psikologi Sastra: Kajian Sastra, Metode, Teori dan Contoh Kasus. Jakarta: Penerbit Obor.
Mujiyanto, Y \& Fuady, A. (2014). Kitab Sejarah Sastra Indonesia. Yogyakarta: Penerbit Ombak.

Pujiharto. (2012). Pengantar Teori Fiksi. Yogyakarta: Penerbit Ombak.

Ridwan, H. (2018). Dinamika Kepribadian Tokoh dalam Novel Di Tanah Lada Karya Ziggy Zezsyazeoviennazabrizkie

Sebuah Kajian Psikoanalisis Sigmund Freud. Jurnal Artikulasi, 2 (1), 1-22.

Sartika, S. \& Ermanto, S. (2018). Emotional Intelligence of Main Children in the Di Tanah Lada Novel. Advances in Social Science, Education and Humanities Research, 206, 505511.

Semium, Y. (2006). Teori Kepribadian Teori Psikoanalsis Freud. Yogyakarta: Kanisius.

Setiari, A.D. dan Supriyanto, T. Struktur Kepribadian dan Emosi Tokoh Utama Pada Novel Serial Anal-anak Mamak. Jurnal Seloka, 5(2), 115-123.

Siswantoro. (2010). Metode Penelitian Sastra. Yogyakarta: Pustaka Pelajar.

Wellek, R dan Werren, A. (2014). Teori Keusastraan. Jakarta: Gramedia Pustaka Utama

Zezsyazeoviennazabriezky, Z. (2015). Di Tanah Lada. Jakarta: Grasindo. 